\title{
REESTRUTURAÇÃO PRODUTIVA DO MUNDO DO TRABALHO E A FORMAÇÃO PROFISSIONAL TECNOLÓGICA
}

\author{
PRODUCTIVE RESTRUCTURING IN THE WORLD OF WORK AND TRAINING \\ TECHNOLOGY
}

Danielle Barbosa Santos*

Robson Luiz de França**

\begin{abstract}
RESUMO
O presente trabalho analisa as questões que envolvem a relação Educação e Trabalho e tem como foco a formação profissional oferecida pelos programas de qualificação em Institutos Federais de Ensino Tecnológico. Possui como objetivo verificar se há uma relação entre a formação do trabalhador egresso dos cursos tecnológicos implantados no município de Uberaba-MG, e a real demanda ou vocação econômica de mão de obra especializada no mercado de trabalho dessa região. Parte-se da consideração que o percurso histórico da Educação Profissional no Brasil se estabeleceu a partir da reestruturação produtiva do mundo do trabalho e alterou de forma profunda as relações entre educação e sociedade, homem e trabalho, escola e mercado de trabalho. Constatase que a política de educação atual coopera para a formação de sujeitos acríticos, pois a uniformização da educação para todos não oferece educação necessária para contribuir na formação do homem crítico e politizado conforme afirmado nos discursos políticos. Apesar do crescimento da escolarização em nível técnico, tecnológico e superior com vistas à formação profissional as empresas não estão conseguindo preencher as vagas que exigem qualificação básica universitária, pois a escola e a Universidade não conseguem acompanhar o movimento dinâmico tecnológico do mercado de trabalho.
\end{abstract}

PALAVRAS-CHAVE: Educação Profissional - Tecnólogo - Mercado de Trabalho.

\section{ABSTRACT}

The present paper examines the issues surrounding the relationship between education and work and focuses on vocational training programs offered by the Federal Institutes of Technology Education. It has to verify whether there is a relationship between the worker's training of graduate courses in technology deployed in the city of Uberaba, Minas Gerais, and the real demand or economic life of skilled labor in the labor market in this region. It starts with the consideration that the historical route of Professional Education in Brazil was established from the restructuring of the productive world of work and changed in a profound way the relationship between education and society, man and work, school and labor market. It appears that the current education policy for the formation of cooperative subjects uncritical, since the standardization of education for all does not provide education to 
contribute to the formation of man and critically politicized as stated in political speeches. Despite the growth in enrollment in technical, technological and above with a view to training companies are failing to fill jobs that require basic academic skills, and the University because the school does not keep up with the technological dynamic movement of the labor market.

KEYWORDS: Professional Education - Technologist - Labor Market.

\section{INTRODUÇÃO}

O tema do presente trabalho corresponde a um campo de pesquisa institucional relacionado com a análise da conjuntura política e educacional das políticas governamentais direcionadas ao mundo do trabalho e à educação, com foco na Formação Profissional oferecida pelo programa de qualificação profissionalizante no Instituto Federal de Ensino Tecnológico de Uberaba, região do Triângulo Mineiro - Minas Gerais. Essa pesquisa está vinculada a Linha de Pesquisa de Política e Gestão da Educação do Programa de Pós-Graduação em Educação da Universidade Federal de Uberlândia.

O objetivo central é analisar a relação entre a formação do trabalhador egresso dos cursos tecnológicos implantados no Instituto Federal de Ensino Tecnológico - IFET Uberaba-MG, e a real demanda ou vocação econômica de mão de obra especializada no mercado de trabalho dessa região.

A formação profissional oferecida pelos programas de qualificação, segundo Alves e Vieira (1995), deve garantir ao trabalhador o acesso às novas tecnologias de produção, assim como buscar atender as exigências do mercado, deverá também garantir a inserção e permanência deste trabalhador no mercado.

\section{BREVE ESBOÇO HISTÓRICO DO ENSINO PROFISSIONALIZANTE NO BRASIL}

A formação do trabalhador no Brasil começou a ser feita desde os tempos mais remotos da colonização, tendo como os primeiros aprendizes de ofícios os índios e os escravos, e "habituou-se o povo de nossa terra a ver aquela forma de ensino como destinada somente a elementos das mais baixas categorias sociais". (FONSECA, 1961, p. 68).

Entre descobertas, avanços e retrocessos, no ano de 1785, o desenvolvimento 
do tecnológico do Brasil ficou estagnado, com a proibição da existência de fabricas obviamente devido o medo de que este viesse a se libertar das ataduras com Portugal, por ser o Brasil um país com abundancia de recursos naturais o que aliado a indústria se tornaria um perigo para as metrópoles.

De acordo com Garcia (2000), em 1808, D. João VI revoga a então estabelecida proibição e cria o Colégio das Fábricas, considerado o primeiro estabelecimento instalado pelo poder público, contudo o objetivo deste era atender à educação dos artistas e aprendizes portugueses.

Anos mais tarde, o então presidente do Estado do Rio de Janeiro, Nilo Peçanha iniciou no Brasil o ensino técnico por meio do Decreto n 787, de 11 de setembro de 1906, criando quatro escolas profissionais naquela unidade federativa, para o ensino de ofícios e aprendizagem agrícola. Após a morte de Afonso Pena, em 1909, Nilo Peçanha assume a Presidência do Brasil e assina o Decreto ํㅜ 7.566, criando inicialmente dezenove Escolas de Aprendizes Artífices em todo o território, as quais eram subordinadas ao Ministério da Agricultura, Indústria e Comércio, marcando oficialmente a implementação do ensino técnico, primário e gratuito.

A partir de 1941, o ensino profissional passou a ser considerado de nível médio, e com o Decreto $\mathrm{n}^{0}$ 4.127, de 1942 as Escolas de Aprendizes e Artífices se transformam em Escolas Industriais e Técnicas, passando a oferecer a formação profissional em nível equivalente ao do secundário. A partir desse ano, inicia-se, formalmente, o processo de vinculação do ensino industrial à estrutura do ensino do país como um todo, uma vez que os alunos formados nos cursos técnicos ficavam autorizados a ingressar no ensino superior em área equivalente à da sua formação. (BRASIL, 2011).

Kuenzer (1997) salienta que era bem demarcada a trajetória educacional daqueles que iriam desempenhar funções intelectuais ou instrumentais numa sociedade que delimitava a divisão social e técnica do trabalho.

No ano de 1959, as Escolas Industriais e Técnicas são transformadas em Escolas Técnicas Federais, estas ganham autonomia didática e de gestão. Com isso, intensifica-se a formação de técnicos, mão de obra indispensável diante da aceleração do processo de industrialização. 
Buscando atender às necessidades do setor produtivo, em nome do desenvolvimento econômico da nação, a educação superior implantou os Cursos Superiores de Tecnologia - CST.

Em 1978, com a Lei nº 6.545, três Escolas Técnicas Federais (Paraná, Minas Gerais e Rio de Janeiro) são transformadas em Centros Federais de Educação Tecnológica - CEFETs, conferindo a estas instituições mais uma atribuição, a de formar engenheiros de operação e tecnólogos, processo esse que se estende às outras instituições bem mais tarde. (BRASIL, 2011).

Na atual Lei de Diretrizes e Bases da Educação, (LDB no 9.394/96, Cap. III, art. 39): "A educação profissional integrada às diferentes formas de educação, ao trabalho, à ciência e à tecnologia conduz ao permanente desenvolvimento de aptidões para a vida produtiva". (BRASIL, 1996, p.10).

Em 1999, retoma-se o processo iniciado em 1978, de transformação das Escolas Técnicas Federais de Educação em Centros Federais de Educação Tecnológica - CEFETs, que têm por finalidade oferecer a educação tecnológica.

Com a expansão dos CST pelo país o Ministério da Educação - MEC faz uma

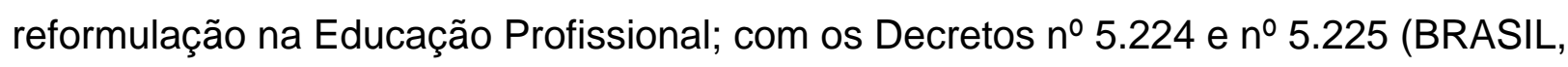
2004) ${ }^{1}$, levando os CEFETs a condição das Universidades Públicas, ou seja, Institutos Federais de Educação Superior.

Em 2007, foi lançada a segunda fase do Plano de Expansão da Rede Federal de Educação Profissional e Tecnológica, tendo como meta entregar à população mais 150 novas unidades, perfazendo um total de 354 unidades, até o final de 2010, cobrindo todas as regiões do país, oferecendo cursos de qualificação, de ensino técnico, superior e de pósgraduação, sintonizados com as necessidades de desenvolvimento local e regional. Contudo atualmente se tem uma relação total de 18 CEFETs e suas 33 UNEDs (Unidades de Ensino vinculadas aos CEFETs).

O enfoque dado a Educação Profissionalizante teve em seu processo histórico várias alterações, hora se apresenta com enfoque de preconceito social, hora de assistencialismo, logo em seguida na busca pela superação dos enfoques anteriores se lança sobre o discurso de inclusão social e democratização dos bens sociais de uma sociedade. 


\section{TRANSFORMAÇÕES NO MUNDO DO TRABALHO E SUAS IMPLICAÇÕES NA EDUCAÇÃO}

Segundo Franco (1998), há várias expressões que tentam, por meio da história, imprimir significado à educação profissional: formação profissional ou técnicoprofissional, educação industrial ou técnico-industrial, qualificação, requalificação e capacitação. Os referidos termos ganham complexidade e novos sentidos levando-se em conta a nova realidade produtiva e a nova reorganização dos processos de trabalho (FRANCO, 1998, p. 67-86).

Pois o mercado ao ser o pólo irradiador dos direcionamentos políticos, econômicos e sociais, determina o aumento da exclusão social. O que, esvazia a possibilidade do estabelecimento de um Estado justo e da existência de cidadãos em condições iguais de participação na sociedade.

Para Noronha, a emergência da noção e do modelo de competências parece vir fortemente associada às novas concepções do mundo da indústria e da empresa, fundadas na flexibilidade e na reconversão permanente, que trazem, em seu interior, componentes como: autonomia, responsabilidade, capacidade de comunicação e polivalência (NORONHA, 2008, p. 30).

Segundo Ramos, é o mundo econômico que vai determinar os conteúdos de ensino e atribuir sentido prático aos saberes escolares. Ao realizar uma análise da transformação da qualificação em competência, conclui que a qualificação se compara com o regime taylorista-fordista, e está associada a uma visão estática do mundo de trabalho. A competência, por sua vez, emerge dos novos modos de produção, de forma dinâmica. que indica que, apesar de a qualificação e a competência não serem opostas, há uma tensão que as afasta e as une dialeticamente (RAMOS, 2010, p. 295).

Os novos paradigmas de competência valorizam a subjetividade e intersubjetividade do indivíduo, exigem ações coletivas, participação na gestão da produção, envolvimento nas estratégias de competitividade da empresa e tudo isso sem alterações salariais. Em seus desdobramentos, o "modelo de competência" surge em 
substituição ao modelo fordista. Um dos seus pontos centrais é a modificação do escopo prescritivo típico do fordismo.

Do ponto de vista do trabalhador, o modelo da competência enfatiza a dimensão da subjetividade, „o modo de ser", a forma de inserção de cada indivíduo na construção coletiva dos processos de trabalho (MACHADO, 1998).

Percebemos a criação de uma qualificação polivalente, nesse sentido Batista (2006) explica que:

\begin{abstract}
É considerado qualificado na lógica do modelo de competências, o trabalhador que possuir "mais do que um estoque de saberes - saber-fazer, saber-ser - aplicáveis ao trabalho, a qualificação", pois o modelo de competências inclui, "necessariamente a capacidade de enfrentar o imprevisto e o imprevisível, de ir além do domínio de tarefas prescritas (BATISTA, 2003, p.162).
\end{abstract}

A polivalência nada mais é que o atributo de um profissional possuidor de competências, que lhe permitem superar os limites de uma ocupação ou campo de trabalho, para transitar em outros campos ou ocupações da mesma área profissional ou áreas afins.

Para Frigotto, são necessários ainda outros requisitos como ter boa formação geral, ser responsável, com capacidade de perceber um fenômeno em processo, não dominando, porém, os fundamentos cientifico-intelectuais do processo (FRIGOTTO, 1997, p.53).

Na prática o que se impõe é que os trabalhadores sejam multifuncionais e não a oferta de uma formação mais integral como muitos querem acreditar. O que se tenta é tornar o processo educativo em espaço de formação de um indivíduo que se identifique diretamente com os interesses da produção, como se estes fossem os seus próprios (SOUZA, 2008, p.119).

O discurso sobre educação e trabalho aponta que é necessário se qualificar cada vez mais para atender as exigências do mercado. Além da formação mínima exigida, é requerido um conjunto de atributos e características pessoais que tornem esse indivíduo mais empregável.

Nesse contexto, fala-se de uma „empregabilidade ${ }^{2 "}$ em relação à qual, um dos requisitos seria a aprendizagem continuada e o desenvolvimento de novas habilidades e competências, em especial as relativas às novas tecnologias de informação e comunicação. Cabe observar aqui que, tanto o modelo de competência como a empregabilidade "trazem 
consigo uma total identidade com a lógica do capital, identificando-se o trabalhador como ser rentável que deve vender sua força de trabalho no mercado" (MACHADO, 1996 - apud GONÇALVES FILHO, 1997).

O desenvolvimento econômico oferece aos participantes do mercado de trabalho oportunidades novas e em rápida mudança (BANCO MUNDIAL, 1995, 26-35) atualmente nos deparamos com a flexibilização da força de trabalho.

A configuração do trabalho se modificou. Em lugar do trabalho em regime de tempo integral e por prazo indeterminado no setor industrial, proliferam formas de trabalho livre de encargos sociais, trabalho temporário, por prazo determinado, em regime de tempo parcial. Emergem formas de trabalho em casa, o trabalho feito por aprendizes e mesmo por estagiários, num processo de redução do tamanho da força de trabalho diretamente empregada. Cresce o poder dos empresários sobre os trabalhadores, o que lhes permite adotar uma autonomia decisória que pouco leva em conta as representações de classe (CARVALHO NETO, 2001).

Nessa perspectiva a precarização do trabalho inclui "formas informais e incompletas de empregos", nas quais os jovens brasileiros mesmo sendo o grupo mais escolarizado é também o que possui maior índice de desempregados ou inserção nessas formas de trabalhos precários, ocorrendo um aumento considerável de desemprego e de desempregados escolarizados.

As grandes corporações, em número reduzido, convivem e nutrem (através de subcontratações) uma rede capilar de modalidades mais ou menos formais de exploração dos trabalhadores. (FONTES, 2008, p. 27)

Partimos da premissa que um dos fatores que geram o desemprego estrutural se dá pela inadequação da formação de mão-de-obra com a necessidade do mercado de trabalho. A política de educação atual coopera para a formação de sujeitos acríticos, pois a uniformização da educação para todos, não garante a oferta de educação de qualidade, há um determinismo de se manter a estrutura de uma educação estratificada por nível social.

Todavia à medida que as mudanças no mercado de trabalho são rápidas, a educação caminha a passos lentos, aquém de uma transformação qualitativa do sistema educacional, contudo se observado os rumos da educação é possível perceber que ela está articulada aos interesses do empresariado que por vez tem maior controle sobre as ações e o desempenho das instituições escolares. Pois o mesmo tem consciência das fragilidades 
do sistema educacional e suas implicações na qualidade da mão-de-obra gerada para 0 setor produtivo, logo, há que se ter o controle da educação bem como darlhe a direção desejada para se obter o resultado necessário a suprir as carências do mercado, fortalecendo a ideologia de que a educação é a cura para os males da sociedade contemporânea.

Em outras palavras, a política de educação atual coopera para a formação de sujeitos acríticos, pois a uniformização da educação para todos não oferece educação de qualidade, há um determinismo de se manter a estrutura, a educação estratificada por nível social.

As empresas e indústrias não estão conseguindo preencher as vagas que exigem qualificação básica universitária, pois a escola e a Universidade não conseguem acompanhar o movimento dinâmico tecnológico do mercado de trabalho. Visto que quanto mais desenvolvida é uma sociedade mais avançada tecnologicamente ela é. Está afirmação é pertinente e incomoda a partir do momento que as indústrias deveriam fomentar a educação, melhorando o nível de escolarização da população brasileira e não esperar apenas que o Estado o faça.

Ao investir em capital humano ${ }^{3}$ qualificado a indústria poderia criar uma base que lhes possibilitaria competir no mercado global e reestruturar sócio-economicamente 0 país. Se ao longo dos anos 60 e 70, a Teoria do Capital Humano dominou fortemente a Educação; na década de 1990, o que podemos perceber é que conceitos como competências e empregabilidade podem estar configurando um ressurgimento ou uma neoteoria do Capital Humano.

No contexto da análise dessa ética empresarial, o eixo principal divulgado pelos formadores dos trabalhadores parece ser a conscientização e a emancipação do sujeito aluno/trabalhador adulto na condição de sujeito social e coletivo. No entanto esse argumento é frágil e percebe-se que fica apenas no campo do marketing empresarial do convencimento do trabalhador, tendo em vista que, o que se vê, de fato, é uma concepção de formação pautada pelo horizonte individualista e da submissão. A nova educação profissional orienta-se pelo conceito de empregabilidade (FRANÇA, 2008, p. 171).

Para Garretón, a atual abordagem dada à educação leva a uma visão distorcida e a uma simplificação da realidade onde: 
Modernidade é igual a modernização; educação é igual a sistema escolar e preparação para o mercado de trabalho; desenvolvimento é igual a crescimento econômico, treinamento para aquisição de conhecimento; e justiça, a igualdade socioeconômica e pluralismo sociocultural (GARRETÓN, 1999, p.88).

Por um lado ocorre um processo ideológico naturalizador da exclusão social e, por outro, a tentativa de redução do processo educativo a um mecanismo instrumental e adaptativo voltado para a integração periférica ou informal no mercado de trabalho.

Arroyo (1980) desenvolveu reflexões sobre as vinculações entre empresa e escola. Para ele, a escola liga-se à empresa pela função socializadora que ela exerce sobre a futura força de trabalho. Essa função socializadora não é desempenhada apenas, nem fundamentalmente, pelos conteúdos que transmite, mas, sobretudo, pela estrutura e organização que a escola encarna.

Maués (2003) aponta que a escola se ocupará de ensinar aquilo que terá utilidade garantida, ou seja, a mudança está posta, pois o conhecimento deixa de ser importante para dar destaque ao saber fazer.

Bezerra cita que para os neoliberais a educação deve estar subordinada às necessidades do mercado de trabalho, ou seja, à urgência de que o sistema educacional se ajuste às demandas do mundo dos empregos. Contudo a função social da educação deve ser a de promover a empregabilidade necessária para competir nesse mercado, o que vem a ser a capacidade flexível de adaptação individual às demandas do mercado de trabalho (BEZERRA, 2008, p.54).

Portanto o estudante haverá de adaptar-se a estrutura escolar que é organizada nos moldes empresariais, logo estará apto ao modelo do mercado de trabalho vigente.

O trabalho e seus desdobramentos passaram a coisificar os homens, visto que estes não mais se enxergam naquilo que produzem. Entre o trabalho prescrito e o trabalho real, há um espaço em que as soluções criadas pelos trabalhadores são fundamentais para que a produção se efetive. 


\section{CONSIDERAÇÕES FINAIS}

O discurso posto pelo neoliberalismo é de que o desemprego do "trabalhador" é a consequência pela não qualificação profissional de sua mão de obra.

O capitalismo produz as injustiças e a escola as mantém. Pois em pleno século XXI, a educação ainda esta restrita a um papel compensatório, encontra-se em um momento de incertezas, por diversas formas de precarização das condições de existência e por fortes processos de exclusão.

A ideia de que todos têm direito a educação remete a ideologia burguesa dominante de que todos devem estar aptos a cooperar nas relações de produção, consequentemente mantendo a dominação e a exploração, como fato natural e do qual não há como fugir.

\section{REFERÊNCIAS BIBLIOGRÁFICAS}

ALVES, E. L. G.;VIEIRA, C. A. dos S. Qualificação profissional: uma proposta de política pública. Brasília: IPEA/DF, 1995.

ARROYO, M. G. Operários e educadores se identificam: que rumos tomará a educação brasileira? Educação e Sociedade. São Paulo: Cortez - Autores Associados, n. 5, p. 5-23, jan. 1980.

BANCO MUNDIAL. Relatório sobre o Desenvolvimento Mundial. O trabalhador e o processo de integração mundial. Washington, 1995.

BATISTA, R. L. Reestruturação Produtiva, Ideologia e Qualificação: Crítica às Noções de Competência e Empregabilidade. In BATISTA, Roberto Leme; ARAÚJO, Renan (Orgs.). Desafios do Trabalho Capital e Luta de classes no século XXI. Londrina: Práxis; Maringá: Massoni, 2003. p.143-172

BEZERRA NETO, L. A classe trabalhadora e a mundialização do saber. In: Carlos Lucena, org. Trabalho, precarização e formação humana - Campinas, SP: Editora Alínea, 2008. p. 54 . 
BRASIL, Lei 9394, de 20 de dezembro de 1996. Estabelece Diretrizes e Bases para a educação nacional. Diário Oficial da República Federativa do Brasil, Brasília, DF, 23 dez. 1996.

BRASIL. Políticas públicas para a educação profissional e tecnológica. Ministério da Educação. Secretaria de Educação Profissional e Tecnológica. Brasília, MEC, 2004.

BRASIL. Ministério da Educação: centenário da rede federal de educação profissional e tecnológica. [Documento eletrônico]. Disponível:

<http://portal.mec.gov.br/setec/arquivos/centenario/historico_educacao_profissional.pdf --> Acesso em: 21 abr. 2011.

BRASIL. Decreto $n^{\circ} 5.224$, de $1^{\circ}$ de outubro de 2004. Dispõe sobre a organização dos Centros Federais de Educação Tecnológica e dá outras providências. [Documento eletrônico]. Disponível em: <http://portal.mec.gov.br/arquivos/pdf/Decreto_5.224.pdf ----> Acesso em: 05 jul. 2011.

BRASIL. Decreto $n^{\circ}$ 5.225, de $1^{\circ}$ de outubro de 2004. Altera dispositivos do Decreto $n^{\circ}$ 3.860, de 9 de julho de 2001, que dispõe sobre a organização do ensino superior e a avaliação de cursos e instituições, e dá outras providências. [Documento eletrônico] Disponível em: <http://portal.mec.gov.br/arquivos/pdf/Decreto_5.225.pdf----> Acesso em: 05 jul. 2011.

CARVAlho neto, A. Relações de Trabalho e Negociação Coletiva na Virada do Milênio. Petrópolis, R.J: Vozes. (2001).

FIDALGO, F. e MACHADO, L., edits. (2000) Dicionário da Educação Profissional. Belo Horizonte: NETE/FAE/UFMG. 5/2/2007 Mesa IV: Cenários: Transformações no Mundo do Trabalho 11 Gonçalves Filho, Cid (2000). Reestruturação Produtiva, Qualificação e 
Trabalho no Brasil - Uma análise crítico-reflexiva in: Caderno de Debates Plural, (13) março/2000, p.22-43.

FONSECA, Celso Suckow. História do Ensino Industrial no Brasil. Rio de janeiro: Escola Técnica, 1961. p. 68.

FONTES, V. Marx, expropriações e capital monetário: notas para o estudo do capitalismo tardio. Rev. Crítica Marxista. № 26, p. 09-31, 2008, p.27.

FRANCO, M. C. Qualificação, formação ou educação profissional? Pensando além da semântica. In: Contexto \& Educação. Jul./set. ljuí: Unijuí, 1998. p. 67 - 86.

FRANÇA, R. L. de O Trabalho como Princípio da Dignidade da Pessoa Humana: Estado, Educação e Cidadania In: Capitalismo, estado e educação Ed. São Paulo: Átomo e Alínea, 2008, v.1, p. 152-176.

FRIGOTTO, Gaudêncio. O local Face ao Nacional e ao Global - Limites e Possibilidades. IN: Revista da ADUEL - SINDIPROL, №. 02, Ano 2, edição 1997, p. 53.

GARCIA, S. R. de O. "O fio da história: a gênese da formação profissional no Brasil”. In: Trabalho e Crítica. São Leopoldo: Ed. UNISINOS, 2000.

GARRETÓN, M. A. (1999) "Cidadania, integração nacional e educação: ideologia e consenso na América Latina", em Albala-Bertrand (org.) Cidadania e educação (Campinas: Papirus) p. 87-102.

KUENZER, A. Z. Ensino médio e profissional: as políticas do Estado neoliberal. São Paulo: Cortez, 1997. (Questões da nossa época; v. 63). p. 12. 
MACHADO, L. (1998) O "Modelo de Competências" e a regulamentação da base curricular nacional e de organização do ensino médio, In: Trabalho e Educação - Revista do NETE, ago/dez 1998, n.4, NETE/FAE/UFMG, Belo Horizonte.

MAUÉS, O. Os organismos internacionais e as políticas públicas educacionais no Brasil. In: GONÇALVES, Luiz Alberto Oliveira (Org.). Currículo e políticas públicas. Belo Horizonte: Autêntica, 2003. p. 10-11.

NORONHA, O. M. Globalização, mundialização e educação. In: LUCENA, C.(org.) Capitalismo, Estado e Educação. - - Campinas, SP: Editora Alínea, 2008.

RAMOS, A. F. Educação, trabalho e formação do trabalhador de nível técnico: políticas públicas sobre educação profissional em Uberlândia-MG - Universidade Federal de Uberlândia, 2010. Dissertação (Mestrado em Educação).

SOUZA, L.M. A nova (e precária) configuração da classe trabalhadora no capitalismo monopolista. In: Carlos Lucena, (org.) ${ }^{4}$ Trabalho, precarização e formação humana Campinas, SP : Editora Alínea, 2008. p. 119.

\footnotetext{
* Graduada em Educação Física pela Universidade Federal de Uberlândia (2007). Especialista em Docência na Educação Superior; mestranda em Educação; colaboradora no Núcleo de Estudos Em Planejamento e Metodologia de Ensino da Cultura Corporal. Atualmente é bolsista CAPES.

** Graduado em Pedagogia pela Faculdade de Filosofia Ciências e Letras de Belo Horizonte (1990), Especializado em Tecnologias para Educação à Distància, mestrado em Educação pela Universidade Federal de Uberlândia (1997). Possui doutorado em Educação na Linha de Politicas Públicas pela

Universidade Julio Mesquista Filho - UNESP/Araraquara. Professor da Faculdade de Educação da Universidade Federal de Uberlândia e atua do Programa de Pós-Graduação em Educação na Linha de Pesquisa em Política e Gestão da Educação.

1

Decreto $\mathrm{n}^{\circ}$ 5.225, de 1ำ de outubro de 2004, consta do Art. 11-A. Os Centros Federais de Educação Tecnológica são instituições de ensino superior pluricurriculares, especializados na oferta de educação tecnológica nos diferentes níveis e modalidades de ensino, caracterizando-se pela atuação prioritária na área tecnológica (BRASIL, 2004).

2 O termo „empregabilidade" suscita grandes controvérsias. Entre suas conceituações, podemos citar a do MTb, 1995: "capacidade de obter emprego, mas sobretudo de manter-se no mercado de trabalho em constante mutação" ( apud GONÇALVES FILHO, 2000). Ou, como visto da perspectiva da consultoria empresarial: a empregabilidade é "garantida por seis pilares - adequação vocacional, idoneidade,
} 
competência, saúde física e mental, reserva financeira e bons relacionamentos (sic) - e que para mantê-la é preciso se comportar como quem sobe uma escada rolante que desce: para subir, tem que andar mais rápido do que o ritmo da escada" (sic) (Dunninghan, A., apud SANTOS, 1997) Para maiores esclarecimentos ver o verbete homônimo (FIDALGO e MACHADO, 2000). 3 O conceito de capital humano consiste em atribuir um valor ao capital incorporado nos seres humanos, fruto da sua experiência, educação, formação e know-how. Este capital seria um factor fundamental do desenvolvimento econômico diferenciado entre países. Este conceito surgiu na década de 1950, criado por Theodore W. Schultz. O conceito foi ainda desenvolvido e popularizado por Gary Becker e retomado, nos anos 80 , pelos organismos multilaterais mais diretamente ligados ao pensamento neoliberal, na área educacional e no contexto dos desafios resultantes da reestruturação. Foi também utilizado nas diretrizes educacionais governamentais do governo Fernando Henrique Cardoso.

ENVIADO EM: 19.10. 2011

APROVADO EM: 24.11.2011 